\title{
1 Estimation of Evapotranspiration and Other Soil Water Budget Components in an 2 Irrigated Agricultural Field of a Desert Oasis, Using Soil Moisture Measurements
}

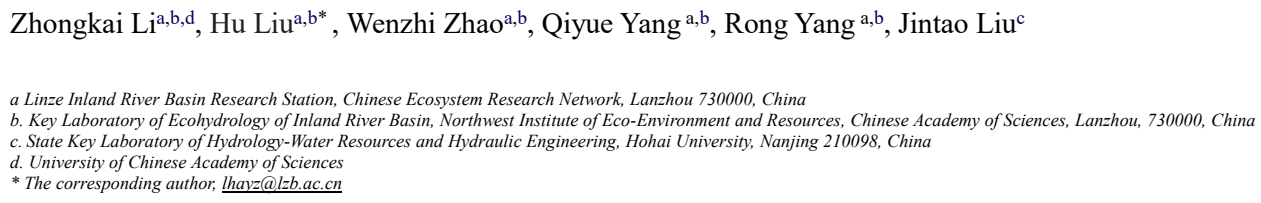

\section{Abstract}

An accurate assessment of soil water budget components $(S W B C s)$ is necessary for improving irrigation strategies and optimizing the use of fertilizer in any water-limited environment such as the desert oases in arid northwestern China. However, quantitative information of $S W B C S$ is usually challenging to obtain, because, since the water cycle is principally driven by irrigation (I), drainage $(D)$, and evapotranspiration (ET) in desert oasis settings, none of the drivers can be easily measured under actual conditions. Soil moisture is a variable that integrates the water balance components of land surface hydrology, and the evolution of soil moisture is assumed to contain the memory of antecedent hydrologic fluxes, and thus can be used to determine $S W B C s$ from a hydrologic balance. A database of soil moisture measurements from six experimental plots in the middle Heihe River Basin of China (NT1 to NT6, designed to investigate the long-term effects of cropping systems and agronomic manipulation on soil property evolution in the ecotone of desert and oasis) was used to test the potential of a soil moisture database in estimating the SWBCs. The experimental plots were treated as continuous pasture cropping, maize cropping, maize cropping with straw return, maize-maize-pasture rotation, maize-pasture rotation, and maize-pasture intercropping. We first compared the hydrophysical properties of the soils in the plots, including soil bulk density $\left(\rho_{b}\right)$, vertical saturated hydraulic conductivity $\left(K_{S}\right)$, and soil water retention features, and then determined evapotranspiration and other $S W B C S$ through a data-driven method that combined both the soil water balance method and the inverse Richards function. Our results showed that although the tillage and planting of the past decade have significantly increased the soils' water-holding ability, the magnitude of increase in most of the parameters was independent of the treatments applied across the plots. Despite the relatively flat topography and consciously uniform irrigation, significant variances were observed among the plots in both the cumulative irrigation volumes (between $652.1 \mathrm{~mm}$ at NT3 and $1186.5 \mathrm{~mm}$ at NT1) and deep drainages (between 170.7 $\mathrm{mm}$ at NT3 and $651.8 \mathrm{~mm}$ at NT1) during the growing season of 2016. Obvious correlation existed between the volume of irrigation and that of drained water. However, the ET demands for all the plots behaved pretty much the same, with the cumulative ET values ranging between 489.1 and $561.9 \mathrm{~mm}$ for the different treatments in 2016, suggesting that the irrigation amounts had limited influence on the accumulated ET throughout the growing season. This work also confirmed that relatively reasonable estimations of the $S W B C s$ in a desert oasis environment can be derived by using soil moisture measurements, and the results will provide a great potential for identifying appropriate irrigation amounts and frequencies, and thus move toward sustainable water resources management, even under traditional surface irrigation conditions.

\section{Keywords}

Evapotranspiration, Soil water budget, Desert oasis, Soil moisture, Inverse Richards Equation.

\section{Introduction}

Arid inland river basins in Northwestern China are unique ecosystems consisting of ice and snow, frozen soil, alpine vegetation, oases, deserts, and riparian forest landscapes, in a delicate eco-hydrological balance (Liu et al., 2015). Among these inland basins, the Heihe river basin (HRB) is one of largest (Chen et al., 2007). The oasis plains in the middle reaches of the HRB have become an important source of grains, including the largest maize seed production center in China (Yang et al., 2015). Crop water requirements in this region are supplied mainly by irrigation from the river and from groundwater (Zhou et al., 2017). According to Wang et al. (2014), agriculture consumes 80 to $90 \%$ of the total water resources in the HRB, and has fundamentally altered the regional hydrological processes and even resulted in eco-environmental deterioration (Zhao and Chang, 2014). Traditional irrigation has low efficiency (i.e., a high leaching fraction) (Deng et al., 2006; Li et al., 2017) and the extensive fertilization practices have given rise to higher levels of potential nitrate contamination in the groundwater, because water and pollutants percolate into the deep 
sandy soils of the desert oasis, which have low water-holding capacities (Zhao and Chang, 2014). It is crucial to adopt a mechanism that can preserve the role of irrigation in food security, yet with minimal consumption of the already scarce water, in order to increase water productivity and conservation. Reducing water drainage and thus nitrate contamination in groundwater, saving water, and increasing water and nitrogen use efficiency, are turning out to be important steps toward sustainable agriculture in this region ( $\underline{\mathrm{Hu}}$

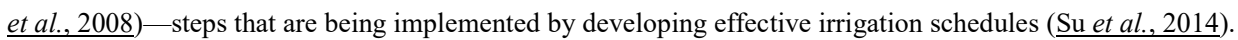

Because allowing the soil to dry out too much may adversely affect the yield and quality of crops, while irrigating too early can lead to wasted water, loss of fertilizer by leaching, increased operating costs and drainage problems, and sometimes decreased crop yield or quality (Wright, 1971), an efficient irrigation scheduling program should aim to replenish the water deficit within the root zone while minimizing leaching below this depth (Bourazanis et al., 2015). Accordingly, an accurate assessment of soil water budget components $(S W B C S)$ is necessary for improving the irrigation management strategies in the oasis field. However, quantitative information of $S W B C s$ is usually challenging to obtain (Dejen, 2015). In desert oasis settings, the water cycle is principally driven by irrigation $(I)$, drainage $(D)$, and evapotranspiration $(E T)$. None of these drivers is easily measured in practice, however. For example, not even the optimal irrigation amount can be determined accurately: the two most common methods of measuring irrigation water - water meters or indirect methods - pose both economic and operational challenges to water managers, due to the wide spatial distribution of small fields throughout rural areas (Folhes et al., 2009). Measurement of deep percolation is also difficult, and reliable data are rare in practice, and thus percolation is often calculated as a residual of the water balance (Bethune et al., 2008; Odofin et al., 2012). ET is another source of uncertainty inherent in water budget estimations (Dolman and De Jeu, 2010), and its estimation is only possible through the application of mathematical models, and is commonly calculated by relying on reference ET $\left(E T_{0}\right)$ or potential ET (PET) (Ibrom et al., 2007; Suleiman and Hoogenboom, 2007; Allen et al., 2011; Wang and Dickinson, 2012).

Soil moisture is a variable that integrates the water balance components of land surface hydrology (Rodriguez-Iturbe and Porporato, 2005), and over time it can be used to develop a record of antecedent hydrologic fluxes (Costa-Cabral et al., 2008). Indeed, the possibility of using changes in soil water content to estimate evaporation and other SWBCs has long been recognized (McGowan and Williams, 1980) (Koksal et al., 2017). Many studies, including Schelde et al. (2011) and Guderle and Hildebrandt (2015), have shown that highly resolved soil moisture measurements contain a great deal of information that can be used to accurately determine ET and sink term, based on hydrologic balance, when the appropriate approach is used. Rahgozar et al. (2012) and Shah et al. (2012) extended these methodologies to determine other components of the water budget, such as lateral flow, infiltration, interception capture, storage, surface runoff, and other fluxes. Time domain reflectometry (TDR) has been widely used in many irrigating regions, including the desert oasis of the middle HRB, during the last decade (Liu et al., 2015), for automated measurement of soil water dynamics, because of its flexibility and accuracy (Schelde et al., 2011). As one of the efforts in this region, intensive TDR measurement of soil moisture was conducted in a long-term field experiment that was originally designed to test the accumulative impacts of different cropping systems (i.e., maize and alfalfa) and agronomic manipulation (i.e., succession cropping, crop rotation, row intercropping) on soil property evolution in the ecotone of desert and oasis. So far, however, no works have been published on testing the potential of using a soil moisture database as a data-driving method in this region.

Based upon a soil moisture database, as mentioned above, this work aimed to 1) investigate the performance of using soil moisture measurements to determine $E T$ and other $S W B C s$ in the croplands of desert oases; 2) estimate the long-term effects of cropping and agronomic manipulation on field water balances by comparing the estimated $E T$ and $S W B C s$ of differently treated plots; and 3) determine the potential for using soil moisture measurements to improve irrigation strategies in the desert oasis.

\section{Materials and Methods}

\subsection{Study area}

The study sites were located in the transition zone between the Badain Jaran Desert and the Zhangye Oasis in the middle HRB (Fig. 1). More specifically, they were in the Linze Inland River Basin Research Station of the Chinese Academy of Science $\left(39^{\circ} 21^{\prime} \mathrm{N}\right.$, $100^{\circ} 17^{\prime} \mathrm{E}$, altitude $1382 \mathrm{~m}$ ). This region has a temperate continental desert climate. The annual average temperature is about $7.6^{\circ} \mathrm{C}$, and the lowest and highest temperatures are $-27^{\circ} \mathrm{C}$ and $39.1^{\circ} \mathrm{C}$ for winter and summer, respectively. The annual average precipitation is $117 \mathrm{~mm}$ and the mean potential evaporation is about $2,366 \mathrm{~mm} / \mathrm{a}$. The annual dryness index is 15.9 . About $60 \%$ of the total precipitation, with low rainfall intensity, is received during July-September, with only $3 \%$ occurring during winter. Northwest winds 
Hydrol. Earth Syst. Sci. Discuss., https://doi.org/10.5194/hess-2018-518

prevail throughout the year, with intense sandstorm activities in spring. This region was part of a sandstorm-eroded area, and the research site was converted into an artificial oasis during the 1970s. As a result, the soil types are dominated by sandy loam and sandy soil, and characterized by coarse texture and rapid infiltration (Zhao et al., 2010). The local dominant species are Scotch Pine, Gansu poplar, wheat, and maize (Liu et al., 2015), and sand-fixation plant species (planted since the 1970s), including Haloxylon ammodendron, Elaeagnus angustifolia, Tamarix ramosissima, Nitraria sphaerocarpa, and annual herbaceous species such as Bassia dasyphylla, Halogeton arachnoideus, Suaeda glauca and Agriophyllum squarrosum. The growing season of these plants and forages usually starts in early April and normally continues through the month of September (DOY 94-288, Julian days $>0{ }^{\circ} \mathrm{C}$ ).
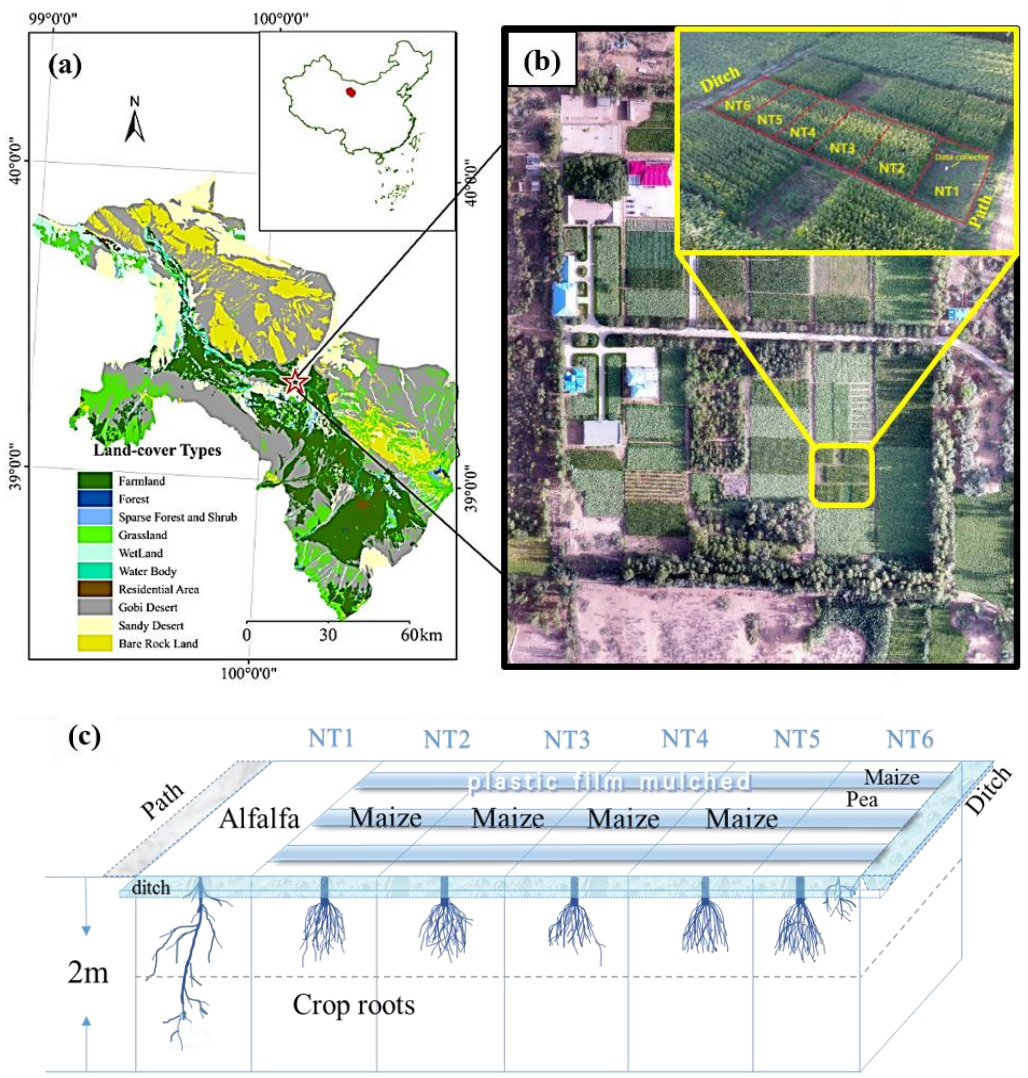

Figure 1. a) Map of study area and research site; b) aerial view of the study site; c) detailed designs of the field experiments in 2016

\subsection{Site description}

In order to investigate the accumulative effect of different cropping systems and agronomic manipulation on soil property evolution, a long-term field experiment with six different treatments was set up in 2007. The experiment was performed with randomized complete block design (RCBD) with three replications (Fig.1 b \& c), so that in total, 18 plots of $6 \mathrm{~m} \times 9 \mathrm{~m}$ were established. We assumed that the soil texture and cultivation history (about 40 years) of the plots subjected to the different treatments were essentially identical before the experiment was conducted. The middle one of the three replications (6 plots, NT1 to NT6) was selected for installing the TDR sensors. The applied treatments of NT1 to NT6 were sequentially as follows: (1) continuous pasture cropping; (2) continuous maize cropping; (3) continuous maize cropping with straw return; (4) maize-maize-pasture rotation; (5) maizepasture rotation; (6) maize-pasture intercropping. Plastic film mulching was applied during the initial growing season, and the irrigation method was furrow irrigation (Zhao et al., 2015). In 2016, NT1 was planted in alfalfa without plastic film mulch; NT2 to NT5 in maize with plastic film mulch; and NT6 in interlaced maize (mulched) and peas (non-mulched) (Fig.1.c). Maize and peas are annual crops, whereas alfalfa is a perennial forage legume which normally lives four to eight years; its root zone depth is between 1 and $2 \mathrm{~m}$ in the sandy soils of this region (Sun et al., 2008). The growing season of maize and alfalfa in the region is usually from early April till late September (Zhao and Zhao, 2014). Alfalfa was harvested twice during the growing season of 2016. Harvest 1 

from a nearby tube well was applied one by one in the plots from NT1 to NT6 during each irrigation event, and this work was usually completed in 3 hours or less. The volumetric soil moisture of the six plots (NT1 to NT6) was measured with TDR systems (5TE, Decagon Devices Inc. Pullman, WA, USA), which were installed at 5 different depths $(20,40,60,80$, and $100 \mathrm{~cm})$ at each plot, with measurement intervals of 10 minutes. Before use, the TDR was calibrated from soil columns in the laboratory with known volumetric water contents $\left(\Theta_{v}\right)$. A maximum likelihood fitting procedure was used to correct the observed data to eliminate the potential errors induced by the soil texture and salinity (Muñoz-Carpena, 2009). Soil bulk density $\left(\rho_{b}\right)$, vertical saturated hydraulic conductivity $\left(K_{S}\right)$, and soil water retention were determined using standard laboratory procedures on undisturbed soil cores in steel cylinders $\left(110 \mathrm{~cm}^{3}\right.$ in volume, $5 \mathrm{~cm}$ in height $)$ taken at $20-\mathrm{cm}$ intervals down to $100 \mathrm{~cm}$ depth. Soil water retention curves were measured at the pressure heads of $-0.01,-0.05,-0.1,-0.2,-0.4,-0.6,-0.8,-1,-2,-5,-10,-15,-20$, and -25 bars. $K_{S}$ was measured with an undisturbed soil core using the constant head method (Salazar et al., 2008). The values of field capacity $\left(\Theta_{f c}\right)$ and wilting point $\left(\Theta_{w}\right)$ were empirically related to the corresponding soil water (matrix) potentials through the determined soil-water retention potential evaporation were recorded by a weather station located near the experimental site.

\subsection{Calculation methods}

\section{1) Water storage and irrigation amount}

Soil water storage $(S)$ was calculated for the soil depth within the root zone $(0-110 \mathrm{~cm})$ based on the sensor readings through the equation:

$$
\mathrm{S}=\sum_{i=1}^{5} \theta_{i} Z_{i}^{\prime}
$$

where $\theta_{i}$ is the soil moisture of layer $i$; and $Z_{i}^{\prime}$ is the layer thickness between $10 \mathrm{~cm}$ above and $10 \mathrm{~cm}$ below the sensor installation depth. At the field level, examples of inflows are irrigation and rainfall, and examples of outflows are evaporation and deep leakage beyond the root zone. An irrigation event usually lasted 20 to 30 minutes in each of the independent plots based upon the growth stages of the plants. Soil moisture increased rapidly following irrigation events and decreased quickly as well during the subsequent dry-down period. Rapid drying usually occurs for a few hours after a soil has been thoroughly wetted because of high water conductivity (Fig. 2). The preferential flow was neglected in the selected soil profiles because the larger hydraulic conductivity of sandy soil itself neutralizes the effects of preferential flow, and because coarse soil is relatively inimical to the formation of stable preferential flow paths (Hamblin, 1985). Because the relatively short irrigation times that hampered the form of the steady infiltration rate (Bautista and Wallender, 1993; Selle et al., 2011), we hypothesized that no surface-water excess or steady-state flow took place during any irrigation events, and assumed that deep percolation began when soil moisture storage reached maximum $\left(\mathrm{S}_{\max }\right)$; thus the irrigation volume $(V)$ could be calculated as the difference between $S_{\max }$ and $S_{\text {ini }}$ :

$$
V=S_{\max }-S_{\text {ini }}
$$

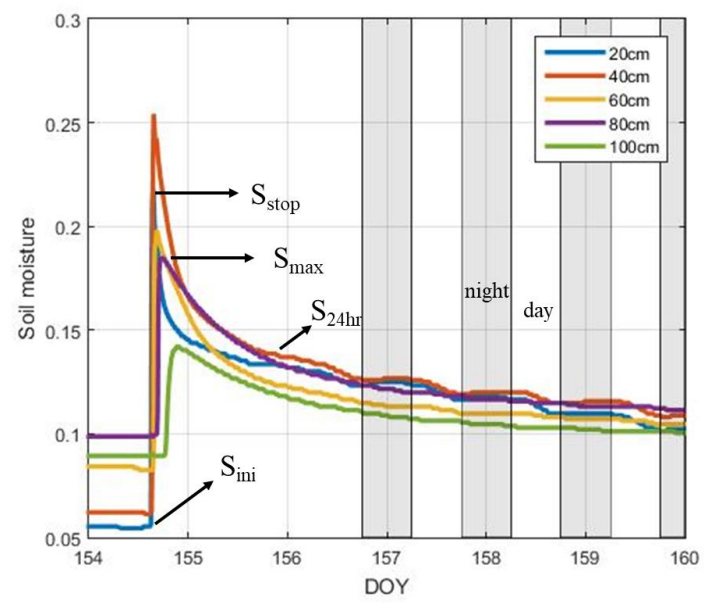


Figure 2. Example diagram of the volumetric soil water content at various depths of NT6 during and after the irrigation event of $107.1 \mathrm{~mm}$ on DOY 154-160 (2016). Sstop: irrigation event ends, and moisture of uppermost soil layer starts to decrease; Smax: water storage maximum: after this point, deep percolation begins; $S_{24 h r}$ : deep percolation ends one day later; after this point, ET dominates the water-loss processes; $S_{\text {ini: }}$ preirrigation, soil moisture minimum. The gray stripes between 156-160 DOY represent nights, i.e., 6:00 pm to 6:00 am of the next day.

\section{2) Drainage and evapotranspiration}

Following irrigation water applications, the drainage behavior of soils consists of two stages: 1) rapid drainage and 2) slow drainage. During irrigation, the root zone becomes effectively saturated, and rapid drainage follows, leading to deep percolation. Then, as the water content in the soil falls, the hydraulic conductivity decreases sharply, as does the rate of drainage. The second phase, slow drainage, may continue for several days or months, depending on the soil texture (Bethune et al., 2008). We assumed that rapid drying or drainage ceased 24 hours after an irrigation event, and thus rapid drainage $\left(Q_{1}\right)$ could be estimated through the variances of water storage and actual ET during the period (Eq. 3). The actual ET during the period was assumed to be equal to the potential ET, because ET occurs unhindered with no water shortage.

$$
Q 1=\mathrm{S}_{\max }-\mathrm{S}_{24 h r}-E T_{p}
$$

where $S_{24 h r}$ is the soil moisture storage 24 hours after irrigation; $S_{\max }$ is the maximum water storage after irrigation; and $E T_{p}$ is the potential ET during that day.

Slow drainage is especially important for sandy soils (Bethune et al., 2008), as along with ET, it dominants the water loss processes during the second drying stage before the next irrigation event. Following Zuo et al. (2002) and Guderle and Hildebrandt (2015), an inverse method was employed to estimate the slow drainages and the average root water uptakes by solving the mixed theta-head formulation of the 1-D Richards Equation (Eq. 4) and iteratively searching for the sink term profile that produces the best fit between the numerical solution and the measured values of soil moisture content. ET is then obtained by summing rainfall and the sink term $\left(S_{p}\right)$, and the drainage for this period is estimated as the water flux across the lower boundary of the soil profile. The above-mentioned 1-D Richards Equation is written as:

$$
\begin{aligned}
& \mathrm{C}(h) \frac{\partial \mathrm{h}}{\partial \mathrm{t}}=\frac{\partial}{\partial \mathrm{t}}\left[K(h)\left(\frac{\partial \mathrm{h}}{\partial \mathrm{z}}-1\right)\right]-S p(z, t) ; \\
& h(\mathrm{z}, 0)=h_{0}(z) \quad 0 \leq z \leq L ; \\
& {\left[-K(h)\left(\frac{\partial \mathrm{h}}{\partial \mathrm{z}}-1\right)\right]_{z=0}=-E(t) \quad t>0 ;} \\
& h(L, t)=h_{l}(t) \quad t>0 ;
\end{aligned}
$$

where $h$ is the soil matric potential $(\mathrm{cm}) ; C(h)$ the soil water capacity $\left(\mathrm{cm}^{-1}\right) ; K(h)$ the soil hydraulic conductivity $\left(\mathrm{cm} \mathrm{d}^{-1}\right) ; h_{0}(z)$ the initial soil matric potential in the profile $(\mathrm{cm}) ; E(t)$ the soil surface evaporation rate $(\mathrm{cm})$ and $h_{l}(t)$ the matric potential at the lower boundary $(\mathrm{cm}) ; L$ the simulating depth $(\mathrm{cm})$; and $z$ the vertical coordinate originating from the soil surface and moving positively downward $(\mathrm{cm})$. The iterative procedure runs the numerical model over a given time step $(\Delta t)$ in order to estimate the soil water content profile $\tilde{\theta}_{i}^{v=0}$ at the end of the time step, assuming that the sink term $\widetilde{S p}_{i m, i}^{(v=0)}$ is zero over the entire profile at the beginning, where $\sim$ depicts the estimated values at the respective soil layer $i$, and $v$ indicates the iteration step. Next, the sink term profile $\widetilde{S p}_{i m, i}^{(v=1)}$ is set equal to the difference between the previous approximation $\tilde{\theta}_{i}^{v=0}$ and the measurements $\theta_{i}$, while accounting for soil layer thickness and the length of the time step for units. In the following iterations, $\tilde{S} p_{i m, i}^{(v)}$ was used with the Richards equation to calculate the new soil water content $\tilde{\theta}_{i}^{v}$. The new average sink term $\widetilde{S p}_{i m, i}^{(v+1)}$ was then determined with Eq. (8):

$$
\widetilde{S p}_{i m, i}^{(v+1)}=\widetilde{S p}_{i m, i}^{(v)}+\frac{\widetilde{\theta}_{i}^{v}-\theta_{i}}{\Delta t} \cdot d_{z, i}
$$

A backward Euler with a modified Picard iteration finite differencing solution scheme was adopted to inversely obtain the solution, and this implementation follows exactly the algorithm outlined by Celia et al. (1990). Three steps proposed by Guderle and Hildebrandt (2015), were taken to determine when the iteration process could be terminated in this calculation:

a. Evaluate the difference between the estimated and measured soil water contents (Eq. 9) and compare the change in this difference to the difference from the previous iteration (Eq. 10):

$$
\begin{gathered}
e_{i}^{(v)}=\left|\theta_{i}-\tilde{\theta}_{i}^{v}\right| \\
\varepsilon_{G H, i}^{(v)}=\left|e_{i}^{(v-1)}-e_{i}^{(v)}\right|
\end{gathered}
$$

b. In soil layers where $\varepsilon_{G H}^{(v)}<0$, set the root water uptake rate back to the value of the previous iteration $\widetilde{S p}_{i m, i}^{(v+1)}=\widetilde{S p}_{i m, i}^{(v-1)}$, since the current iteration was no improvement. Only if $\varepsilon_{G H}^{(v)} \geq 0$, go to the next step. 
Hydrol. Earth Syst. Sci. Discuss., https://doi.org/10.5194/hess-2018-518

c. If $e_{i}^{(v)}>1 \times 10^{4}$, calculate $\widetilde{S p}_{i m, i}^{(v+1)}$ according Eq. (8); otherwise the current iteration sink term $\left(\widetilde{S p}_{i m, i}^{(v+1)}=\widetilde{S p}_{i m, i}^{(v)}\right)$ is retained, as it results in a good fit between estimated and measured soil water content.

\section{3) Boundary setting and data collection}

To reduce computational complexity, uniform soil profiles were assumed because there were no significant stratification differences within the sandy soils (Table2) (Liu et al., 2015). The upper boundary of the calculation was set as the atmospheric boundary condition, and the calculation involved actual precipitation, irrigation, and potential evapotranspiration rates for the crop cover. The surface fluxes were incorporated by using the average hourly rates distributed uniformly over each hour. The lower boundary condition was set as a free drainage boundary because the groundwater table depth (deeper than $3.5 \mathrm{~m}$ ) was far below the crop effective root depth during the growing season, and any capillary rise from groundwater could be ignored in this study. A unit vertical hydraulic gradient boundary condition (i.e., $h=-5 \mathrm{~cm}$ ) was implemented in the simulation in the form of a variable flux boundary condition. The drainage rate $q(n)$ assigned to the bottom node $n$ was determined by the software as $q(n)=-K(h)$, where $h$ is the local value of the pressure head and $K(h)$ is the hydraulic conductivity corresponding to this pressure head (Odofin et al., 2012). The meteorological measurements were monitored at the nearby weather station and were used to compute the upper boundary condition. The potential ET used to force the boundary conditions was calculated with the Penman-Monteith combination equation using hourly environmental data during the period from 1 April to 30 September (Fig. 3). We used soil moisture dynamics measured

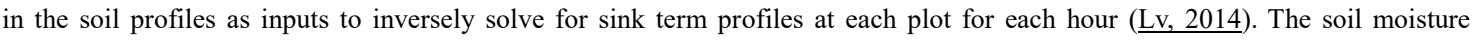
measurements of 10-minute intervals during the period were hourly averaged to numerically filter out the noise associated with highly resolved data. This had the effect of slightly reducing the infiltration and ET estimates, but this effect in the overall results is negligible according to Guderle and Hildebrandt (2015). The actual amount of water delivered for irrigation $\left(Q_{0}\right)$ was determined from the power consumption of water pumping $\left(P_{0}\right)$ through a relationship established between the power consumption and the water pumping: $Q_{0}=P_{0} \times \eta$, where $\eta$ is the ratio of the power consumption per unit water pumped and is likely to be different for different pumping heads. The coefficient was experimentally determined to be $8.5 \mathrm{~m}^{3} \mathrm{~kW}^{-1} \mathrm{~h}^{-1}$ for a head corresponding to $0.95 \mathrm{~kg} / \mathrm{cm}^{2}$ of delivery pressure in this study.

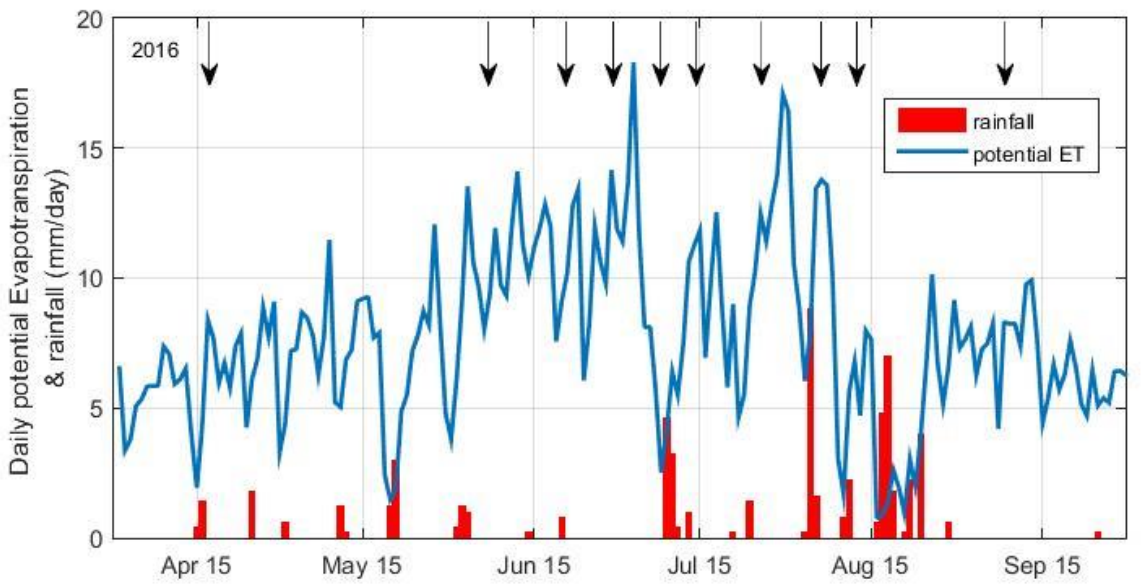

Figure 3. Measured daily rainfall and potential ET estimated with the Penman-Monteith method during the growing season of 2016 at Linze Station. The cumulative rainfall during the growing season was $69.2 \mathrm{~mm}$ in 2016 , and the black down arrows represent irrigation events.

\begin{tabular}{|c|c|c|c|}
\hline$\overline{\mathrm{V}}$ & irrigation amount for one irrigation event (mm) & $\mathrm{K}(\mathrm{h})$ & soil hydraulic conductivity $\left(\mathrm{cm} \mathrm{d}^{-1}\right)$ \\
\hline $\mathrm{S}$ & soil water storage $(\mathrm{mm})$ & $\mathrm{h}_{0}(\mathrm{z})$ & initial soil matric potential in the profile $(\mathrm{cm})$ \\
\hline$S_{\text {stop }}$ & soil moisture storage when irrigation was stopped (mm) & $\mathrm{E}(\mathrm{t})$ & soil surface evaporation rate $(\mathrm{cm})$ \\
\hline$S_{\text {ini }}$ & soil moisture storage before irrigation start (mm) & $h_{l}(t)$ & matric potential at the lower boundary $(\mathrm{cm})$ \\
\hline$S_{24 \mathrm{hr}}$ & soil moisture storage 24 hours after irrigation $(\mathrm{mm})$ & $\mathrm{L}$ & simulation depth $(\mathrm{cm})$ \\
\hline$S_{\max }^{2 n i t}$ & maximum soil water storage during irrigation event $(\mathrm{mm})$ & $\mathrm{z}$ & $\begin{array}{l}\text { vertical coordinate originating from the soil surface and moving } \\
\text { positively downwards }(\mathrm{cm})\end{array}$ \\
\hline$\theta_{i}$ & volumetric soil water content of layer $i(100 \%)$ & $\tilde{\theta}_{i}^{v=0}$ & $\begin{array}{l}\text { soil water content profile of soil layer } i \text { at the beginning of each } \\
\text { calculation }\end{array}$ \\
\hline
\end{tabular}


Hydrol. Earth Syst. Sci. Discuss., https://doi.org/10.5194/hess-2018-518

Manuscript under review for journal Hydrol. Earth Syst. Sci.

Discussion started: 15 October 2018

\begin{tabular}{|c|c|c|c|}
\hline$\Theta_{v}$ & $\begin{array}{l}\text { theoretical volumetric water content calculated by the ratio of soil } \\
\text { volume to water volume }(100 \%)\end{array}$ & $\widetilde{S p}_{i m, i}^{(v=0)}$ & $\begin{array}{l}\text { sink term of soil layer } i \text { at the beginning of irrigation, assuming it } \\
\text { is zero }\end{array}$ \\
\hline$\eta$ & ratio of the power consumption per unit water pumped & $d_{\mathrm{z}, \mathrm{i}}$ & thickness of soil layer $i$ \\
\hline $\mathrm{t}$ & time & $\sim$ & estimated values at soil layer $i$ \\
\hline$Q$ & steady-state drainage $(\mathrm{mm})$ & $v$ & iteration step \\
\hline$E T_{p}$ & potential ET during irrigation day $(\mathrm{mm})$ & $\tilde{\theta}_{i}^{v}$ & soil water content of step $v$ \\
\hline$Z_{i}^{\prime}$ & detection range of TDR, i.e., $20 \mathrm{~cm}$ & $\tilde{S p}_{i m, i}^{(v)}$ & average sink term of step $v$ \\
\hline $\mathrm{S} p$ & sink term, i.e., water extraction by roots, evaporation, etc. $(\mathrm{cm})$ & $\Delta t$ & given time step \\
\hline $\mathrm{h}$ & soil matric potential $(\mathrm{cm})$ & $\varepsilon_{G H, i}^{(v)}$ & difference between and \\
\hline $\mathrm{C}(\mathrm{h})$ & soil water capacity $\left(\mathrm{cm}^{-1}\right)$ & $e_{i}^{(v)}$ & difference between estimated and measured soil water content \\
\hline$Q_{0}$ & real amount of water delivered for irrigation (m3) & $P_{0}$ & power consumption $(\mathrm{kWh})$ \\
\hline$D_{\text {seas }}$ & $\begin{array}{l}\text { theoretical drainage volume over entire growing season in } 2016 \\
(\mathrm{~mm})\end{array}$ & $R_{\text {seas }}$ & cumulative rainfall during entire growing season in $2016(\mathrm{~mm})$ \\
\hline$V_{\text {seas }}$ & $\begin{array}{l}\text { theoretical irrigation volume over entire growing season in } 2016 \\
(\mathrm{~mm})\end{array}$ & $E T_{\text {seas }}$ & $\begin{array}{l}\text { theoretical ET volume during entire growing season in } 2016 \\
(\mathrm{~mm})\end{array}$ \\
\hline$\Delta \mathrm{S}$ & $\begin{array}{l}\text { difference in soil water storage before and after the growing season } \\
(\mathrm{mm})\end{array}$ & $\rho_{b}$ & soil bulk density $\left(\mathrm{g} / \mathrm{cm}^{3}\right)$ \\
\hline$K_{s}$ & saturated water conductivity (cm/day) & $\Theta_{S}$ & saturated water content $(100 \%)$ \\
\hline$\Theta_{f c}$ & field capacity $(100 \%)$ & $\Theta_{w}$ & wilting point $(100 \%)$ \\
\hline$S_{w}$ & wilting point $(100 \%)$ & $S^{*}$ & water stress point $(100 \%)$ \\
\hline$S_{f c}$ & field capacity $(100 \%)$ & $S_{1}$ & saturated water content $(100 \%)$ \\
\hline
\end{tabular}

\section{Results}

\subsection{Soils' hydrophysical properties}

A summary of most important hydrophysical characteristics of the soils at 0-100 cm depth (NT1 to NT6, and two other representative fields) in relation to their capacity for water storage is listed in Table 4 . The textures were largely loamy sandy in the plots of NT1-NT6, in contrast to the sandy loam soil in an old oasis field with a long tillage history ( 100 years) and the sandy soil in the desert with no tillage history (Table 2). Their bulk densities were generally between 1.4 and $1.5 \mathrm{~g} / \mathrm{cm}^{3}$ — slightly higher than that in the local desert land, but still lower than that in maize fields of the old oasis. $\Theta_{s}, \Theta_{f c}$ and $\Theta_{w}$ of the plots showed the same tendency of increasing soil hydrophysical properties (toward better water retention) as the bulk densities (Table 2). However, those parameters of the soil profiles are very similar to each other, especially between the same soil depths (horizontal) of the plots, suggesting that the different planting systems had similar influences on the soil hydrophysical proprieties, at least at the scale of 10 years. The effects of different cropping systems on soil moisture release characteristics are shown in Fig. 4. As expected, the relationship between soil water potential and volumetric water content across all data and treatment combinations followed a curvilinear pattern, where the water potential increased exponentially as soil water content increased.

The profile averaged values of saturated drainage velocity $\left(K_{S}\right)$ were $119,129.36,286.04,189.42,207.92$, and $216.14 \mathrm{~cm}^{-1 a y}{ }^{-1}$ at NT1-NT6, respectively, which are coherent with the permeability results obtained in the laboratory with soil cores obtained from the same soils (Table 2). The large and varying values of $K_{S}$ showed a great drainage potential in the coarse-textured soil and an obvious heterogeneity in both horizontal and vertical profiles across the six plots. Soil moisture characteristic curves (SMC) in the six profiles are shown in Fig. 4, which indicates almost the same soil water content of NT1-NT6 under the same suction head, i.e., all the soil profiles were nearly saturated when the water potential reached the -0.01 bar and little was available after the soil water potential dropped to the -15 bar. Two obvious inflection points were observed, at $\theta \cong 0.08$ and $0.3, \Psi \cong-0.32$ and -15.2 bar in each of soil moisture characteristic curves from NT1-NT6. The slopes of the soil water potential-moisture, especially the parts between the inflection points of the six plots, were very close to each other, and also similar to that of the desert soil, suggesting

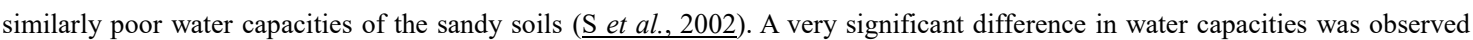
when comparing the SMC of NT1-NT6 with that of the old oasis field, indicating that a considerably long period of time is still needed, for high soil water capacity to evolve, for these experimental sites.

249

Table 2. Soil physical characteristics in the six experiment plots and two other selected plots around the study site

\begin{tabular}{|c|c|c|c|c|c|c|c|c|c|c|c|c|c|c|c|c|c|c|c|c|}
\hline & \multicolumn{5}{|c|}{ NT1 } & \multicolumn{5}{|c|}{ NT2 } & \multicolumn{5}{|c|}{ NT3 } & \multicolumn{5}{|c|}{ NT4 } \\
\hline & $K_{s}$ & $\rho_{b}$ & $\Theta_{s}$ & $\Theta_{f c}$ & $\Theta_{w}$ & $K_{s}$ & $\rho_{b}$ & $\Theta_{S}$ & $\Theta_{f c}$ & $\Theta_{w}$ & $K_{s}$ & $\rho_{b}$ & $\Theta_{S}$ & $\Theta_{f c}$ & $\Theta_{w}$ & $K_{S}$ & $\rho_{b}$ & $\Theta_{s}$ & $\Theta_{f c}$ & $\Theta_{w}$ \\
\hline $20 \mathrm{~cm}$ & 47.2 & 1.38 & 0.36 & 0.25 & 0.09 & 183 & 1.46 & 0.34 & 0.19 & 0.08 & 44.3 & 1.40 & 0.36 & 0.21 & 0.09 & 54.1 & 1.39 & 0.38 & 0.21 & 0.08 \\
\hline $40 \mathrm{~cm}$ & 46.8 & 1.55 & 0.33 & 0.21 & 0.06 & 82.1 & 1.55 & 0.32 & 0.15 & 0.05 & 259 & 1.54 & 0.34 & 0.18 & 0.06 & 266 & 1.50 & 0.36 & 0.17 & 0.06 \\
\hline $60 \mathrm{~cm}$ & 166 & 1.48 & 0.35 & 0.20 & 0.06 & 118 & 1.53 & 0.34 & 0.20 & 0.05 & 73.8 & 1.53 & 0.35 & 0.19 & 0.05 & 355 & 1.47 & 0.36 & 0.16 & 0.06 \\
\hline $80 \mathrm{~cm}$ & 61.0 & 1.45 & 0.33 & 0.17 & 0.05 & 164 & 1.48 & 0.35 & 0.18 & 0.05 & 1007 & 1.46 & 0.35 & 0.18 & 0.05 & 192 & 1.47 & 0.35 & 0.20 & 0.06 \\
\hline $100 \mathrm{~cm}$ & 273 & 1.46 & 0.34 & 0.18 & 0.05 & 99.7 & 1.49 & 0.34 & 0.15 & 0.05 & 46.1 & 1.44 & 0.35 & 0.16 & 0.05 & 80.0 & 1.40 & 0.37 & 0.23 & 0.06 \\
\hline $\bar{X}$ & 119 & 1.46 & 0.34 & 0.20 & 0.06 & 129 & 1.50 & 0.34 & 0.17 & 0.06 & 286 & 1.47 & 0.35 & 0.18 & 0.06 & 189 & 1.45 & 0.36 & 0.19 & 0.06 \\
\hline & & & & & & & & & & 7 & & & & & & & & & & \\
\hline
\end{tabular}


Hydrol. Earth Syst. Sci. Discuss., https://doi.org/10.5194/hess-2018-518

\begin{tabular}{|c|c|c|c|c|c|c|c|c|c|c|c|c|c|c|c|c|c|c|c|c|}
\hline \multirow[t]{3}{*}{$S D$} & \multirow{2}{*}{\multicolumn{5}{|c|}{$\begin{array}{l}0.01 \\
\text { NT5 } \\
\end{array}$}} & \multirow{2}{*}{\multicolumn{5}{|c|}{$\begin{array}{l}0.01 \\
\text { NT6 }\end{array}$}} & 413 & 0.06 & 0.01 & 0.02 & 0.02 & 126 & 0.05 & 0.01 & 0.03 & 0.01 \\
\hline & & & & & & & & & & & \multicolumn{5}{|c|}{ Maize field in old oasis } & \multicolumn{5}{|c|}{ Local desert land } \\
\hline & $K_{S}$ & $\rho_{b}$ & $\Theta_{s}$ & $\Theta_{f c}$ & $\Theta_{w}$ & $K_{s}$ & $\rho_{b}$ & $\Theta_{s}$ & $\Theta_{f c}$ & $\Theta_{w}$ & $K_{S}$ & $\rho_{b}$ & $\Theta_{s}$ & $\Theta_{f c}$ & $\Theta_{w}$ & $K_{s}$ & $\rho_{b}$ & $\Theta_{s}$ & $\Theta_{f c}$ & $\Theta_{w}$ \\
\hline $20 \mathrm{~cm}$ & 121 & 1.42 & 0.37 & 0.24 & 0.09 & 89.6 & 1.50 & 0.32 & 0.25 & 0.09 & 28.8 & 1.61 & 0.38 & 0.29 & 0.11 & 42.5 & 1.46 & 0.36 & 0.16 & 0.05 \\
\hline $40 \mathrm{~cm}$ & 168 & 1.46 & 0.34 & 0.19 & 0.07 & 575 & 1.53 & 0.33 & 0.20 & 0.06 & 20.2 & 1.61 & 0.37 & 0.28 & 0.12 & 48.1 & 1.46 & 0.35 & 0.17 & 0.05 \\
\hline $60 \mathrm{~cm}$ & 41.3 & 1.39 & 0.40 & 0.29 & 0.09 & 66.5 & 1.45 & 0.37 & 0.18 & 0.05 & 37.4 & 1.56 & 0.38 & 0.28 & 0.10 & 30.9 & 1.44 & 0.39 & 0.20 & 0.07 \\
\hline $80 \mathrm{~cm}$ & 38.3 & 1.49 & 0.37 & 0.21 & 0.05 & 331 & 1.50 & 0.34 & 0.18 & 0.04 & 76.3 & 1.59 & 0.37 & 0.24 & 0.09 & 33.3 & 1.45 & 0.33 & 0.18 & 0.05 \\
\hline $100 \mathrm{~cm}$ & 671 & 1.47 & 0.34 & 0.19 & 0.06 & 18.6 & 1.47 & 0.35 & 0.14 & 0.04 & 47.5 & 1.58 & 0.40 & 0.29 & 0.12 & 26.9 & 1.43 & 0.28 & 0.17 & 0.03 \\
\hline $\bar{X}$ & 208 & 1.45 & 0.36 & 0.22 & 0.07 & 216 & 1.49 & 0.34 & & 0.06 & 42 & 1.59 & 0.38 & 0.28 & 0.11 & 36 & 1.45 & 0.34 & 0.17 & 0.05 \\
\hline$S D$ & 265 & 0.04 & 0.02 & 0.04 & 0.02 & 234 & 0.03 & 0.02 & 0.04 & 0.02 & 22 & 0.02 & 0.01 & 0.02 & 0.01 & 9 & 0.01 & 0.04 & 0.02 & 0.01 \\
\hline
\end{tabular}

$K_{s}$ : saturated water conductivity $\left(\mathrm{cm} /\right.$ day); $\rho_{b}$ : bulk density $(\mathrm{g} / \mathrm{cm} 3): \Theta_{s}:$ saturated water content $(100 \%) ; \Theta_{f c}$ : field capacity $(100 \%)$ and $\Theta_{w}$ :
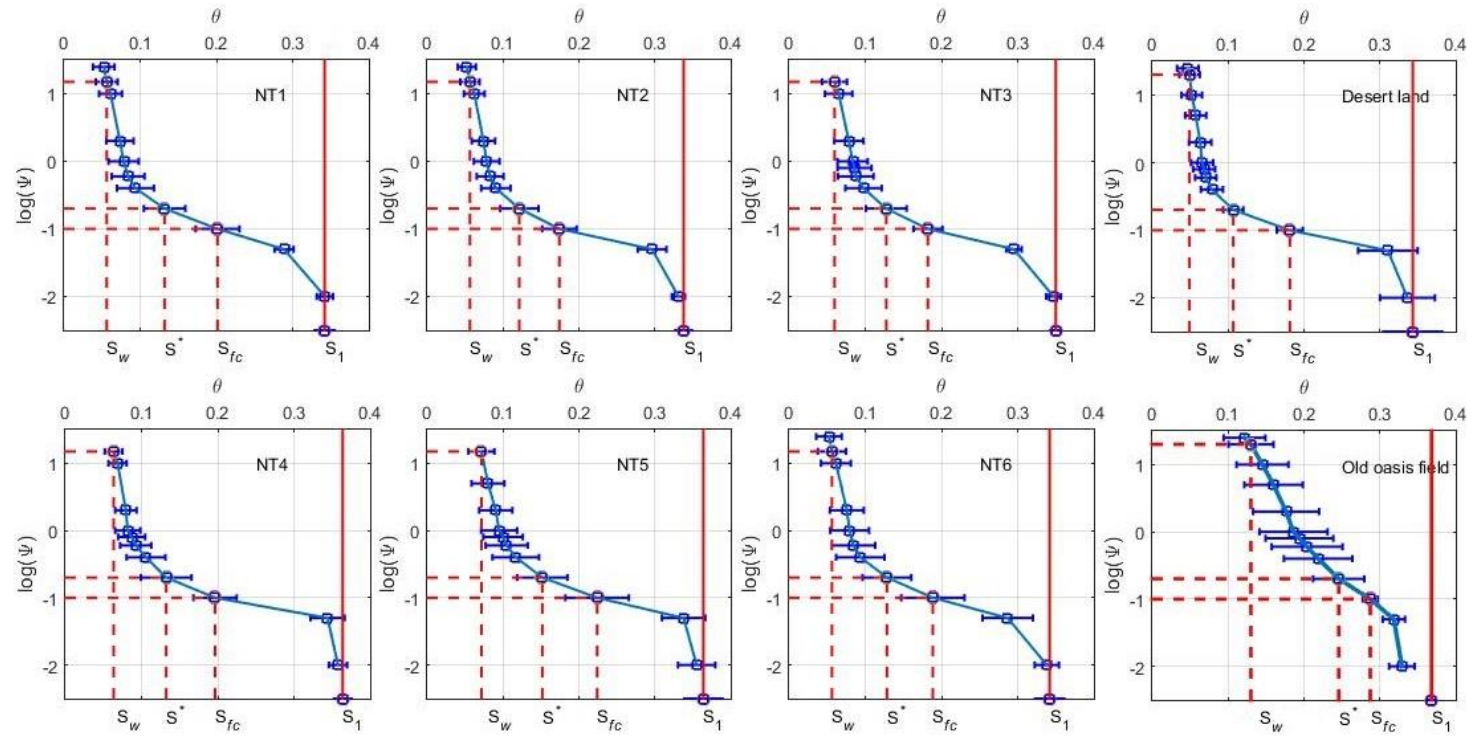

Figure 4. Soil moisture characteristic curve (SMC) of uniform soil profiles of the six experiment plots and two other representative fields. Soil field capacity $\left(S_{f c}\right)$, wilting point $\left(S_{w}\right)$, and water stress point, i.e., point of incipient stomatal closure $\left(S^{*}\right)$ are empirically related to the corresponding soil matric potentials (-0.1 bar for $S_{f c},-0.2$ bar for $S^{*}$ and -15 bar for $\left.S_{w}\right)$; the blue horizontal line represents the error bar, and the solid red line represents saturated water content $\left(S_{1}\right)$, which was obtained via the traditional Soil Drying method with 3 repetitions in each layer; for soil water (matric) potential ( $\Psi$ ) take the absolute value, for example, -0.01 bar is equal to -2 on the Y axis.

\subsection{Meteorological and irrigation data}

The mean temperature of the growing season in 2016 was $27.12^{\circ} \mathrm{C}$, or 3.12 degrees Celsius warmer than the long-term average of the growing seasons in $2007-2016\left(24.0^{\circ} \mathrm{C}\right)$, and the mean rainfall during the period was about $60.2 \mathrm{~mm}$, or 47 percent less than the long-term average of $115.4 \mathrm{~mm}$ (2005-2016), indicating that the weather was hotter and drier during the growing season in 2016 than in the previous ten years. Irrigation was delivered at a rate of $2250 \mathrm{~L} \cdot \mathrm{ha}^{-1} \cdot \mathrm{min}^{-1}$ by way of traditional furrow irrigation. Fig. 7 presents a summary of the amount of water applied over the entire growing season of 2016. Irrigation applications began in midApril and continued until late September, every 5 to 25 days, depending upon moisture content and crop growth (Fig. 3). A total of 10 irrigation events were sequentially applied through furrow irrigation for the plot during the entire growing season. The cumulative irrigation volumes for the plots of NT1 to NT6 during the period were about 1187, 760, 652, 840, 683, and $867 \mathrm{~mm}$, respectively. The estimated average irrigation crop demand within the plots was $831.6 \mathrm{~mm}$, which compares well with the actual irrigation volume $(868.8 \mathrm{~mm})$ determined through power consumption, suggesting that the calculated irrigation agrees closely with the measured values from the farm fields when accurate irrigation and rainfall data are available. A difference of $4.5 \%$ in the irrigation amount was observed between the real values and the measured values over the entire growing season of 2016, indicating a high reliability of the water balance method used in $S W B C S$ estimation.

\subsection{Soil moisture dynamics (SMDs)}

Fig 2 shows an example of the soil water content responses at various depths of NT6 during and after the irrigation event of 107.1 mm on DOY 154 (2016). TDR measurements exhibited a sharp increase when irrigation began and then decreased rapidly as it was turned off, due to the poor water-holding capacity of the sandy soil. The increase in water content occurred layer by layer from the 
upper horizons, suggesting limited influence from potential preferential flow (Liu and Lin, 2015), while the rapid moistening of the deep horizons could imply the existence of water loss by drainage. The greatest rate decrease in water content was observed in the top $20 \mathrm{~cm}$ of soil. During the $12 \mathrm{~h}$ after irrigation, the water content at the top sensor decreased from $21.9 \%$ to $14.2 \%$. For the same interval of time the water contents in 40,60, 80 and $100 \mathrm{~cm}$ depths of soil decreased from $25.4 \%, 19.8 \%, 18.5 \%$ and $14.2 \%$ to $15.7 \%, 14.3 \%, 15.4 \%$ and $12.8 \%$, respectively. After irrigation ended, water continued to move down the soil profile; and thus the top part of the profile was continuously losing water to the soil below it. The lower soil horizons were leaching water into the horizon below but at the same time were receiving water that had drained from the horizon immediately above, resulting in lower rates of decrease in water content for these layers than for those at the top horizon (20 cm) (Fares and Alva, 2000). Very similar patterns of changes in water content through the six different soil profiles were observed.

The average field capacity value $\left(\Theta_{f c}\right)$ of NT6 determined from laboratory measurement of soil water release curves was $19 \%$. Within 24 hours after the end of irrigation, the soil moisture values for the all the measured horizons $(20-100 \mathrm{~cm}$ depth) of NT6 ranged between $12.3 \%$ and $14.2 \%$, lower than the field capacity (Fig.2), suggesting that the rapid drainage of water away from the root zone soil $(0-100 \mathrm{~cm})$ was terminated during the period, as expected. In the mornings of the subsequent days, the decrease in soil moisture again sped up as the evaporative demand of the atmosphere gradually increased. In the absence of any irrigation during the subsequent nights, a slow-down or even a very light increase in the soil moisture content was observed in the top soil layer (Fig 2). We checked all the soil moisture time series of NT1-NT6 during the entire growing season period (Fig.5), and no constant water content throughout the entire soil profile was detected in any of those selected plots, suggesting that our previous hypothesis that no steady-state flow took place during any irrigation events was supported. According to the data, there was also no obvious response of soil moisture regimes to precipitation, indicating a very limited contribution of rainfall to the soil water storage compared with irrigation. In fact, more than $90 \%$ of the rainfall events in this region are less than $5 \mathrm{~mm}$ (Fig. 3), and canopy interception (about 2 $5 \mathrm{~mm}$ ) and strong potential evaporation may have hampered any effective infiltration from those precipitation events.

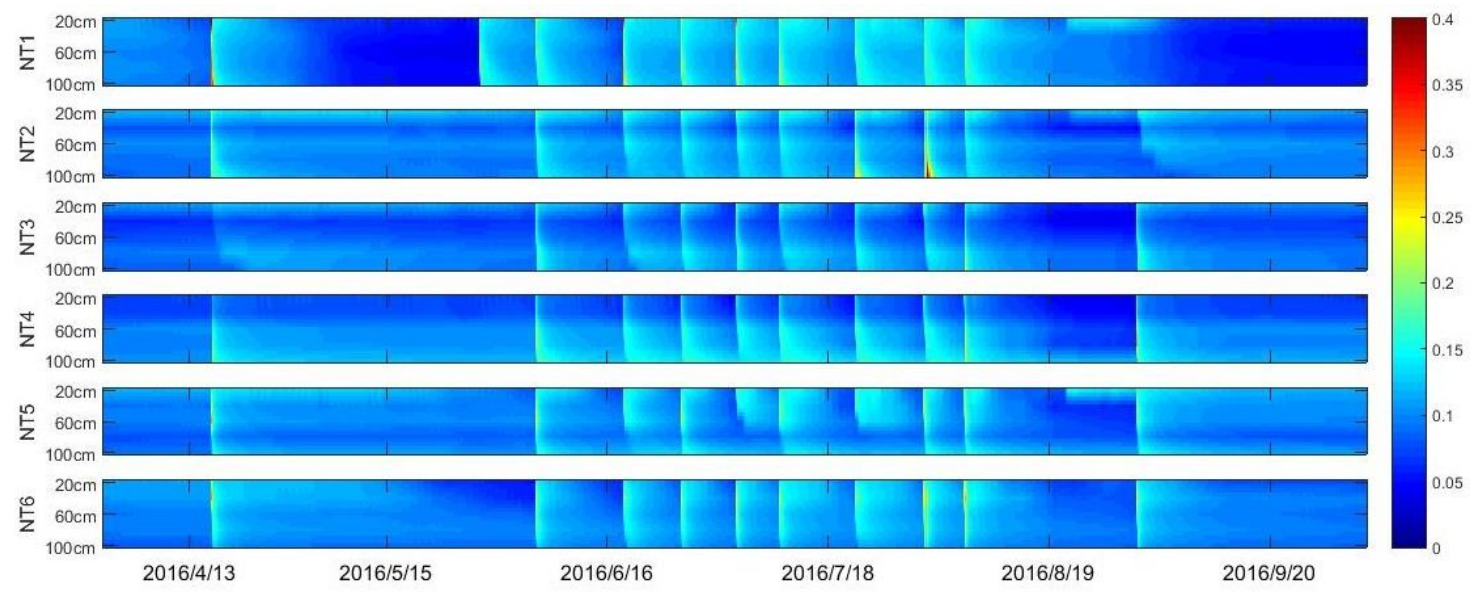

Figure 5. Spatial and temporal variations of soil water content with a time resolution of ten minutes. The color bar on the right side represents volumetric soil water content. Time period was from Apr.1 to Oct.1, 2016. Irrigation events for NT2-6 occurred on 4/16, 6/2, 6/15, 6/23, 7/1, 7/7, $7 / 18,7 / 28,8 / 3$, and $8 / 28$. NT1 had one more irrigation event on $5 / 25$ and one less on $8 / 28$.

\subsection{Soil water budget components $(\mathrm{SWBCS})$}

The estimated soil water budget components, including total irrigation, deep percolation, and $E T$, at the six different plots during the growing season of 2016 are summarized in Table 3 and Fig. 7. Evapotranspiration and deep percolation dominated the fields' relatively simple soil water budgets during the study period. A clear trend in seasonal variation of the water budget components can be observed at the site (Fig. 7). The corresponding ET values were very similar for all the plots. Three different stages of ET could be discriminated throughout the 2016 growing season: ET rate was very low at the initial stage (i.e., the first 50 days of the growing season), and increased gradually as LAI became greater with crop development, before reaching maximal values at the mid-season stage. After that, ET decreased gradually until harvest time. The estimated daily ET values ranged largely between $0.2 \mathrm{and} 12 \mathrm{~mm}$ $\mathrm{d}^{-1}$, with an average of $3 \mathrm{~mm} \mathrm{~d}^{-1}$. No significant differences were detected in the daily ET when Duncan's multiple range test was 
Hydrol. Earth Syst. Sci. Discuss., https://doi.org/10.5194/hess-2018-518

applied at the 5\% level to compare among the six experimental plots $(P>0.75)$. A relatively large difference was observed between selected plots in this study, i.e., significant higher cumulative irrigation volume was found at NT1. The relative facility with which an excess of water in the soil was produced caused an important deep percolation, which became greater as it progressed further up the irrigation gradient. Among the plots, $45-79 \%$ of the input irrigation water was consumed by way of ET (i.e. for plant growth), while the change in soil water storage before and after the growing season was quite small. It is clear that although there was a high correlation between the volume of irrigation and that of drained water, the irrigation amount had limited influence on the accumulated ET during the growing season.

Table 3. Estimated evapotranspiration and other major soil water budget components during the growing season of 2016

\begin{tabular}{ccccccc}
\hline Cumulative SWBCs & NT1 & NT2 & NT3 & NT4 & NT5 & NT6 \\
\hline Irrigation & 1186.5 & 760.1 & 652.2 & 840.4 & 683.2 & 867.3 \\
\hline Drainage & 651.8 & 288.3 & 170.7 & 340.1 & 212.4 & 364.7 \\
\hline ET & 534.6 & 489.1 & 508.8 & 561.9 & 539.2 & 538.1 \\
\hline Storage diff. $*$ & -52.7 & 0.17 & 3.6 & 2.2 & 5.44 & -11.64 \\
\hline
\end{tabular}

* Storage differences represent the difference in soil water storage before and after the growing season.
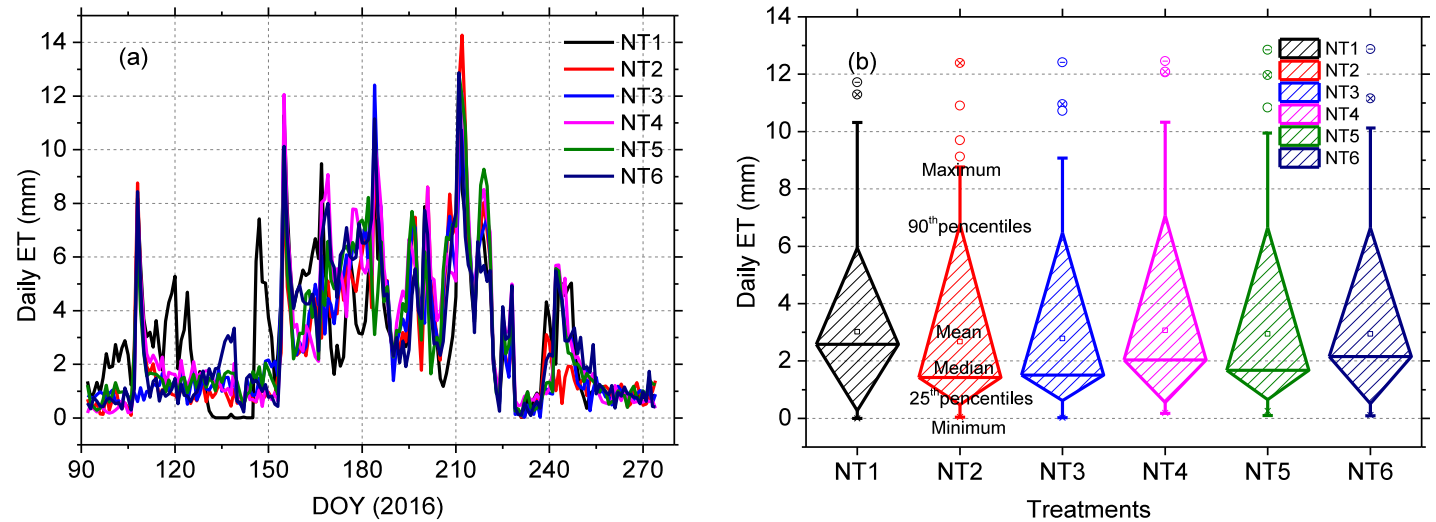

Figure 6. Daily ET during the growing season of 2016 as determined from the inverse Richards method: a) time series of estimated daily ET, b) box-and-whisker diagrams showing the minimum, median, 25th percentile, 75 th percentile, and maximum daily ET. No significant differences were detected when Duncan's multiple range test was applied at the $5 \%$ level to compare values among the plots.
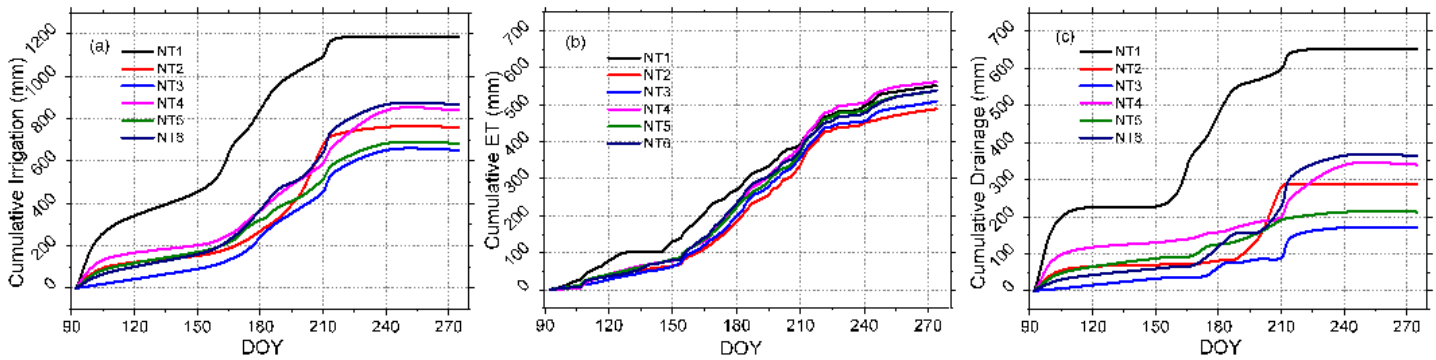

rigure 7.

\section{Discussion}

\subsection{Estimated ET}

Cumulative ET values calculated from inverse Richards methods ranged between 489.1 and $561.9 \mathrm{~mm}$ for the different treatments in 2016. The values of ET obtained from the current study are well within the range of published ET values at the nearby sites (406$778 \mathrm{~mm})$, and are consistent with the averages from other studies $(\sim 585.5 \mathrm{~mm})$ also done in this region, including Zhao and Ji (2010); Rong (2012); Yang et al. (2015); You et al. (2015); Zhao et al. (2015), etc. for maize fields similar to the ones present at the study site (Table 4). Compared with the methods used in the literatures listed in Table 4, the soil moisture data-driven method used in this 
paper is more reliable because it produced the best fit between the numerical solution and the measured values of soil moisture content, even with vertical flow accounted for (Guderle and Hildebrandt, 2015). The narrow range of cumulative ET (489.1-561.9 $\mathrm{mm}$ ) observed in 2016 can be attributed to the similar sandy soil texture and mesic moisture regimes caused by frequent irrigation (Fig. 5), which in turn suggested that both cropping systems and agronomic manipulation had limited influence on the accumulated ET during the growing season (Srivastava et al., 2017). This result is well supported by the evidence reported by early investigators, that the ET differences in different cropping systems are smaller for coarse-textured soils compared with fine-textured soils (Jalota and Arora, 2002), and that ET is strictly a function of ambient atmospheric conditions under normal or wet conditions (ㄹahgozar et al., 2012).

The observed seasonal trend of ET corresponded well to the irrigation frequency and crop water consumption characteristics of the growth stage (Fig. 7), and similar patterns in the ET processes have also been reported by many other works conducted in this region (Zhao et al., 2010; Zhao et al., 2015). Although we also noticed that the cumulative ET of NT1 was relatively higher than those of the other plots at the beginning of growing season, this phenomenon can be largely attributed to the plastic film mulching at the other five plots. In the early growing season (seeding to emergence), soil evaporation (E) is the major part of ET (Zhao et al., 2015), and the plastic film mulching applied to NT2 to NT6 was able to significantly retain the soil moisture and thus decrease soil evaporation (Jia et al., 2006). However, the differences in the cumulative ET, between NT1 and the other plots, were quite small after the mid-growing season, most likely because with the plant canopy development, crop transpiration became the major portion of ET, and the influence of plastic film on ET diminished (Jia et al., 2006; Qin et al., 2014; Zhang et al., 2017). Another influence that may have decreased the evapotranspiration at NT1 after the mid-growing season is cutting. Cutting alfalfa lowers the leaf area index (LAI) and drastically changes the effective diffusive resistance, consequently lowering the daily ET rate of alfalfa at NT1, although for a short time after cutting, evaporation from the soil surface may compensate for the decrease in transpiration (Dong et al., 2003; Su et al., 2010).

Table 4. Reported ET of oasis maize field in the middle Heihe River Basin (HRB)

\begin{tabular}{|c|c|c|c|c|c|c|c|}
\hline ET $(\mathrm{mm})$ & Growing period & Year & Soil type & Irrigation & Rainfall & Methods & Paper \\
\hline 651.6 & Apr.11-Sep.18 & 2001 & --- & 690 & 84.4 & Water balance methods & (Su et al., 2002) \\
\hline 513.2 & Apr.16-Sep.22 & 2005 & Light loam & 360 & 153.5 & Bowen ratio method & (Jinkui et al., 2007) \\
\hline 486.2 & Apr.16-Sep.22 & 2005 & Light loam & 360 & 153.5 & Reference ET-crop coefficient method & (Jinkui et al., 2007) \\
\hline 777.75 & Apr.21-Sep.15 & 2007 & Sandy loam & 1194 & 102.1 & Bowen ratio method & (Zhao et al., 2010) \\
\hline 693.13 & Apr.21-Sep.15 & 2007 & Sandy loam & 1194 & 102.1 & Penman & (Zhao et al., 2010) \\
\hline 618.34 & Apr.21-Sep.15 & 2007 & Sandy loam & 1194 & 102.1 & Penman-Monteith & (Zhao et al., 2010) \\
\hline 615.67 & Apr.21-Sep.15 & 2007 & Sandy loam & 1194 & 102.1 & Water balance method & (Zhao et al., 2010) \\
\hline 560.31 & Apr.21-Sep.15 & 2007 & Sandy loam & 1194 & 102.1 & Priestley-Taylor & (Zhao et al., 2010) \\
\hline 552.07 & Apr.21-Sep.15 & 2007 & Sandy loam & 1194 & 102.1 & Hargreaves method & (Zhao et al., 2010) \\
\hline 671.2 & Apr.10-Sep. 20 & 2009 & Sandy loam & 797 & 97.7 & FAO-56-PM and dual crop coefficient method & (Zhao and Ji, 2010 \\
\hline 640 & Apr.10-Sep.20 & 2009 & --- & 797 & 97.7 & Shuttleworth-Wallace dual-source model & (Zhao et al., 2015) \\
\hline $570-607$ & Apr.22-Sep.23 & 2010 & Loamy sand & $990-1103$ & 75 & Field experiments & (Rong, 2012) \\
\hline 405.5 & Apr.20-Sep.22 & 2012 & Clay loam & 553 & 95.9 & Water balance and isotope methods & (Yang et al., 2015) \\
\hline 450.7 & Apr.20-Sep.22 & 2012 & --- & 430 & 104.9 & Eddy covariance system & (You et al., 2015) \\
\hline 554.0 & Apr.20-Sep.22 & 2012 & --- & 430 & 104.9 & Penman & (You et al., 2015) \\
\hline $489-562$ & Apr.10-Sep.20 & 2016 & Sandy soil & $652-867$ & 60.2 & Inverse method & This paper \\
\hline
\end{tabular}

\subsection{Other estimated $S W B C s$}

The irrigation volume of maize (NT2 to NT6) within our plots ranged between 652.2 and $867.3 \mathrm{~mm}$, with an average value of 760.6 $\mathrm{mm}$, which is well comparable to the range of average maize field irrigation volume in this region, i.e., a range between 604.8 and $811.4 \mathrm{~mm}$ reported in the Statistical Yearbook of Zhangye City for the period of 1995 to 2017 (see http://www.zhangye.gov.cn). When compared to the other treatments of plastic film mulching, significantly higher amounts of the applied irrigation (1186.5 mm) were found in NT1, which could be attributed to the larger percentage of infiltrating surface area and the relatively longer irrigation duration caused by rougher surface of the ground without plastic film mulching. According to Yang et al. (2018), plastic film mulch has been widely used to increase the productivity of crops in arid or semiarid regions of China. The logic behind this approach is that plastic film mulch improves the soil physical properties, such as the soil water content and temperature in the top soil layers, and thus leads to increased plant growth and yield ( $\mathrm{N}$. Mbah et al., 2010). Our results suggested that plastic film mulching can equally reduce irrigation duration and applied water depth by lowering surface roughness and thus the friction coefficient of the ground. Similar results were also reported by earlier investigators (Jia et al., 2006; Qin et al., 2014; Zhang et al., 2017). 
randomly rough soil surfaces, and mutation of the infiltration rate (i.e., $K_{s}$ ) across the plots (Table 2). Uneven irrigation may be further attributed to the uneven fields and ditches, which may lead to the application of much more water than required for evapotranspiration, in some places (Babcock and Blackmer, 1992). Soil surface texture has a direct effect on soil water and complex interactions with other environmental factors (Yong et al., 2014). The hydraulic behavior and the rate of traditional surface irrigation is eventually influenced by the inflow and duration of each irrigation (Ascough and Kiker, 2002). Although only slight differences exist among the retention curves (Fig. 4), the differences in saturation water conductivity $\left(K_{S}\right)$ can be substantial (varying between $119 \mathrm{~cm} /$ day at NT1 and $286 \mathrm{~cm} /$ day at NT3), indicating that a slight difference in hydrophysical properties of soil profiles could be amplified to generate wildly varying infiltration behavior, especially during saturated or near-saturated stages under actual irrigation conditions (Ojha et al., 2017).

Estimated deep drainage rates were observed, ranging from $170.7 \mathrm{~mm}$ (NT3) to $651.8 \mathrm{~mm}$ (NT1), amounting to about $26.2 \%$ and $54.9 \%$ of the total irrigation of the two plots, respectively. Compared with the theoretical deep drainage determined by water balance techniques (Rice et al. 1986), an error of -2.6 to $43.1 \mathrm{~mm}$, or $0.2 \%$ to $17.6 \%$, was obtained for the cumulative deep drainage (Table 3 ), indicating the reliability of the method used to estimated deep drainage in this study. Drainage within the maize fields ranged from $170.7 \mathrm{~mm}$ to $364.7 \mathrm{~mm}$, which are in good agreement with other results from the same region, i.e., $255 \mathrm{~mm}$ through isotopes obtained by Yang et al. (2015), and $339.5 \mathrm{~mm}$ through the Hydrus-1D model by Dong-Sheng et al. (2015). The data expressed in Fig. 2 also explain how easily an excess of water, and therefore deep drainage, can occur in these soils. Indeed, the deep drainage was directly proportional to the amount of irrigation applied during any particular period (Fig. 7, Table 3). This phenomenon is easy to understand because for a given amount of irrigation, the likelihood of a drainage event and its average size both increased naturally with the irrigation amount (Fig.7) (Keller, 2005). It is obvious that drainage should be an essential part of irrigation design and management. According to our results, an average of $40.6 \%$ of input water was consumed by deep leakage across the six plots; this is unproductive and could even cause nutrient loss and groundwater pollution at field scales (Fares and Alva, 2000), suggesting there is a huge potential for increasing irrigation water-use efficiencies and reducing irrigation water requirements in this region.

\subsection{Long-term effects on soil water budgets}

Long-term cropping can increase annual water productivity by improving soil hydrophysical properties and reducing unproductive water losses (Caviglia et al., 2013). Through the physical mechanical actions and active release of chemicals, crop root systems may create heterogeneity in soil properties (Hirobe et al., 2001; Read et al., 2003); this and other similar feedbacks between long-term planted crops and the soil environment change water flow and soil hydraulic characteristics, and thus affect local water balances (Baldocchi et al., 2004; Séré et al., 2012). Although it is difficult to quantify the consequences of plant-soil feedbacks on the hydrologic cycle of farmland, because of the lack of an accurate simulation model (Jalota and Arora, 2002), our results indicated that the tillage and planting of past decades have significantly increased the soil water holding ability (i.e., higher values of $\rho_{b}, \Theta_{S}$, $\Theta_{f c}$ and $\Theta_{w}$ compared with the sandier land). The magnitude of increase in most of the parameters, except $K_{s}$ in soil vertical profiles, was independent of the treatments applied across the six selected plots, which also suggests that different cropping systems and agronomic manipulation have limited effects on differing soil physical characteristics in sandy soil, at least at a decade scale, and this agrees well with the reports from Katsvairo et al. (2002). However, we argue that significant differences in soil hydrophysical properties among the plots may occur if the treatments are conducted over longer periods of time, i.e., $\sim 100$ years or more.

\subsection{Potential for $S W B C$ estimation by using soil moisture measurements}

Information on SWBCs is crucial for irrigation planning at both the field and regional scale (Jalota and Arora, 2002), and the best estimates should be based on models of soil water, because direct measurements are not available in most cases (Campbell and Diaz, 1988). Many studies including modeling work have been conducted in this region during the past decades (Table 4). Since there has been a lack of accurate parameters to assess the heterogeneity and complexity involved in modeling (Ibrom et al., 2007; Suleiman and Hoogenboom, 2007; Allen et al., 2011; Wang and Dickinson, 2012), however, most of these were rough approximations based on meteorological methods and water balance equations (Ji et al., 2007; Rong, 2012; Wu et al., 2015; Yang et al., 2015; Jiang et al. 2016). Data-driven methods have been considered one of the most promising ways to directly determine ET and other SWBCs ( $\underline{\mathrm{Li}}$ et al., 2002; Guderle and Hildebrandt, 2015), and many possible options, including single- or multi-step, and single- or multi-layer water balance methods, have been proposed and tested with synthetic time series of water content (Guderle and Hildebrandt, 2015). Our results suggest that a combination of a soil water balance method and the inverse method could be a good candidate for SWBC 
estimation in this region, and can provide a reliable solution, especially in regards to estimating ET, root water uptake, and water vertical flow, and do not require any prior information of root distribution parameters, while they can be applicable under both wet and dry weather conditions (Guderle and Hildebrandt, 2015).

Early researches suggested that decreasing the irrigation amount and increasing the irrigation frequency is the best choice for saving water and improving water use efficiency in the middle HRB ( $\underline{\mathrm{Ji} \text { et al., 2007; Rong, 2012; }}$ Wu et al., 2015; Yang et al., 2015; Jiang et al., 2016). This scenario can be achieved not only by adopting proper modern irrigation systems but also by integrating new technologies into the effective planning of irrigation schedules, so that plants can be supplied with optimal water volume and minimum water loss. Soil water budget models help in translating irrigation amounts in different time periods to evapotranspiration (ET), which has significance from the standpoint of crop yield (Jalota and Arora, 2002). Our results show that superfluous irrigation has no effect on increasing ET, because of the poor water-holding capacity of the sandy soil in this region, and thus irrigation application should not exceed a specific threshold (i.e., root zone depletion, $\sim 527 \mathrm{~mm}$ for maize) to avoid deep percolation, which has a negative effect: increasing irrigation costs (Zotarelli et al., 2016). However, water deficits in crops and the resulting water stress on plants also influences crop evapotranspiration and crop yield (Kallitsari et al., 2011). Thus, a soil moisture measurement method based on SWBC estimation makes it possible to quantify water budget components for different time periods, and has great potential to identify appropriate irrigation amounts and frequencies, thus moving toward sustainable water resources management, even under traditional surface irrigation conditions (Tawara et al., 2015).

\section{Conclusions}

A database of soil moisture measurements in 2016 from a long-term field experiment (which was originally designed to test the accumulative impacts of different cropping systems and agronomic manipulation on soil-property evolution in the ecotone of desert and oasis) conducted in the middle Heihe River Basin of China was used to test the potential of a soil-moisture time series in estimating the SWBCs. We compared the hydrophysical properties of the soils in the plots, and then determined evapotranspiration and other $S W B C S$ through a data-driven method that combines both the soil water balance method and the inverse Richards function. Our results showed that although the tillage and planting of the past decade have significantly increased the soil water-holding ability, the magnitude of increase in most of the parameters was independent of the treatments applied across the plots, at least during a 10-year period. Despite the relatively flat topography and similar soil hydrophysical properties, significant variances were observed among the plots in both cumulative irrigation volumes (between $652.1 \mathrm{~mm}$ at NT3 and $1186.5 \mathrm{~mm}$ at NT1) and deep drainages (between $170.7 \mathrm{~mm}$ at NT3 and $651.8 \mathrm{~mm}$ at NT1) during the growing season of 2016. Obvious correlation existed between the volume of irrigation and that of drained water. However, the ET demands for all the plots behaved pretty much the same, with the cumulative ET values ranging between 489.1 and $561.9 \mathrm{~mm}$ for the different treatments in 2016, suggesting that superfluous irrigation has no effect on increasing ET because of the poor water-holding capacity of the sandy soil in this region. This work confirmed that a relatively reasonable estimation of the $S W B C S$ in a desert oasis environment can be derived through a data-driven method using soil moisture measurements, and the estimated results of the $S W B C s$ will provide a great potential for optimizing irrigation strategies, thus moving toward sustainable water resources management in this water-limited environment.

\section{Acknowledgements}

This research was supported in part by the National Natural Science Foundation of China (Grant 91425302, PI: Shaozhong Kang and Wenzhi Zhao) and the Youth Innovation Promotion Association of Chinese Academy of Sciences (Grant, PI: Hu Liu).

\section{References}

Allen R, Irmak A, Trezza R, Hendrickx JMH, Bastiaanssen W, Kjaersgaard J. 2011. Satellite-based ET estimation in agriculture using SEBAL and METRIC. Hydrological Processes, 25: 4011-4027. DOI: 10.1002/hyp.8408.

Ascough GW, Kiker GA. 2002. The effect of irrigation uniformity on irrigation water requirements. Water S A, 28: 235-241. DOI: 10.4314/wsa.v28i2.4890.

Babcock BA, Blackmer AM. 1992. The Value of Reducing Temporal Input Nonuniformities. Journal of Agricultural \& Resource Economics, 17: 335-347. 
Baldocchi DD, Xu L, Kiang N. 2004. How plant functional-type, weather, seasonal drought, and soil physical properties alter water and energy fluxes of an oak-grass savanna and an annual grassland. Agricultural \& Forest Meteorology, 123: 13-39. DOI: 10.1016/j.agrformet.2003.11.006.

Bautista E, Wallender WW. 1993. Reliability of Optimized Furrow-Infiltration Parameters. Journal of Irrigation \& Drainage Engineering, 119: 784-800. DOI: 10.1061/(ASCE)0733-9437(1993)119:5(784)

Bethune MG, Selle B, Wang QJ. 2008. Understanding and predicting deep percolation under surface irrigation. Water Resources Research, 44: 681-687. DOI: 10.1029/2007WR006380.

Bourazanis G, Rizos S, Kerkides P. 2015. Soil water balance in the presence of a shallow water table. In: Proceedings of 9th World Congress: Water Resources Management in a Changing World: Challenges and Opportunities.

Campbell GS, Diaz R. 1988. Simplified soil-water balance models to predict crop transpiration. In: Drought Research Priorities for the Dryland Tropics, ICRISAT, pp: 207-210.

Caviglia OP, Sadras VO, Andrade FH. 2013. Modelling long-term effects of cropping intensification reveals increased water and radiation productivity in the South-eastern Pampas. Field Crops Research, 149: 300-311. DOI: 10.1016/j.fcr.2013.05.003.

Celia MA, Bouloutas ET, Zarba RL. 1990. A general mass-conservative numerical solution for the unsaturated flow equation. Water Resources Research, 26: 1483-1496. DOI: 10.1029/WR026i007p01483.

Chen R, Kang E, Ji X, Yang J, Wang J. 2007. An hourly solar radiation model under actual weather and terrain conditions: A case study in Heihe river basin. Energy, 32: 1148-1157. DOI: 10.1016/j.energy.2006.07.006.

Costa-Cabral MC, Richey JE, Goteti G, Lettenmaier DP, Feldkotter C, Snidvongs A. 2008. Landscape structure and use, climate, and water movement in the Mekong River basin. Hydrological Processes, 22: 1731-1746. DOI: 10.1002/hyp.6740.

Dejen ZA. 2015. Hydraulic and operational performance of irrigation schemes in view of water saving and sustainability: sugar estates and community managed schemes In Ethiopia. CRC Press/Balkema.

Deng XP, Shan L, Zhang H, Turner NC. 2006. Improving agricultural water use efficiency in arid and semiarid areas of China. Agricultural Water Management, 80: 23-40. DOI: 10.1016/j.agwat.2005.07.021.

Dolman A, De Jeu R. 2010. Evaporation in focus. Nature Geoscience, 3: 296-296. DOI: 10.1038/ngeo849.

Li D, Ji X, Zhao LW. 2015. Simulation of Seed Corn Farmland Soil Moisture Migration Regularity in the Midstream of the Heihe River Basin. Arid Zone Research, 3: 467-475. DOI: 10.13866/j.azr.2015.03.08.

Dong X, Hong XU, Ji-Cun PU. 2003. Extraction of Remote Sensing Information of Spring Crops Under Support of GPS and GIS in Yunnan Province. Agricultural Meteorology, 24: 35-37. DOI: 10.3969/j.issn.1000-6362.2003.04.011.

Fares A, Alva AK. 2000. Evaluation of capacitance probes for optimal irrigation of citrus through soil moisture monitoring in an entisol profile. Irrigation Science, 19: 57-64. DOI: 10.1007/s002710050001

Folhes MT, Rennó CD, Soares JV. 2009. Remote sensing for irrigation water management in the semi-arid Northeast of Brazil. Agricultural Water Management, 96: 1398-1408. DOI: 10.1016/j.agwat.2009.04.021

Guderle M, Hildebrandt A. 2015. Using measured soil water contents to estimate evapotranspiration and root water uptake profiles - a comparative study. Hydrology and Earth System Sciences, 19: 409-425. DOI: 10.5194/hess-19-409-2015.

Hamblin AP. 1985. The influence of soil structure on water movement, crop root growth, and water uptake. Advances in Agronomy, 38: 95-158. DOI: $10.1016 / \mathrm{S} 0065-2113(08) 60674-4$

Hirobe M, Ohte N, Karasawa N, Zhang GS, Wang LH, Yoshikawa K. 2001. Plant species effect on the spatial patterns of soil properties in the Muus desert ecosystem, Inner Mongolia, China. Plant \& Soil, 234: 195-205. DOI: 10.1023/A:1017943030924

Hu K, Li B, Chen D, Zhang Y, Edis R. 2008. Simulation of nitrate leaching under irrigated maize on sandy soil in desert oasis in Inner Mongolia, China. Agricultural Water Management, 95: 1180-1188. DOI: 10.1016/j.agwat.2008.05.001.

Ibrom A, Dellwik E, Flyvbjerg H, Jensen NO, Pilegaard K. 2007. Strong low-pass filtering effects on water vapour flux measurements with closedpath eddy correlation systems. Agricultural \& Forest Meteorology, 147: 140-156. DOI: 10.1016/j.agrformet.2007.07.007

Jalota SK, Arora VK. 2002. Model-based assessment of water balance components under different cropping systems in north-west India. Agr Water Manage, 57: 75-87.

Ji X, Kang E, Chen R, Zhao W, Zhang Z, Jin B. 2007. A mathematical model for simulating water balances in cropped sandy soil with conventional flood irrigation applied. Agricultural Water Management, 87: 337-346. DOI: 10.1016/j.agwat.2006.08.011.

Jia Y, Li F, Wang X, Yang S. 2006. Soil water and alfalfa yields as affected by alternating ridges and furrows in rainfall harvest in a semiarid 
environment. Field Crops Research, 97: 167-175. DOI: 10.1016/j.fcr.2005.09.009.

Jiang Y, Zhang L, Zhang B, He C, Jin X, Bai X. 2016. Modeling irrigation management for water conservation by DSSAT-maize model in arid northwestern China. Agricultural Water Management, 177: 37-45. DOI: 10.1016/j.agwat.2016.06.014

Wu J, Ding Y, Wang G, Yusuke Y, Jumpei K. 2007. Evapotranspiration of Seed Maize Field in Arid Region. Journal of Irrigation and Drainage, 26: 14-17. DOI: $10.3969 /$ j.issn.1672-3317.2007.01.004.

Kallitsari C, Georgiou PE, Babajimopoulos C. 2011. Evaluation of Crop Water-Production Functions under Limited Soil Water Availability with SWBACROS model. In: "European Federation for Information Technology in Agriculture, Food and the Environment World Congress on Computers in Agriculture.

Katsvairo T, Cox WJ, Van Es H. 2002. Tillage and Rotation Effects on Soil Physical Characteristics. Agronomy Journal, 94: 299-304. DOI: 10.2134/agronj2002.0299

Keller A. 2005. Evapotranspiration and Crop Water Productivity: Making Sense of the Yield-ET Relationship. In: World Water and Environmental Resources Congress, pp: 1-11.

Koksal ES, Tasan M, Artik C, Gowda P. 2017. Evaluation of financial efficiency of drip-irrigation of red pepper based on evapotranspiration calculated using an iterative soil water-budget approach. Scientia Horticulturae, 226: 398-405. DOI: 10.1016/j.scienta.2017.08.025.

Li X, Tong L, Niu J, Kang S, Du T, Li S, Ding R. 2017. Spatio-temporal distribution of irrigation water productivity and its driving factors for cereal crops in Hexi Corridor, Northwest China. Agricultural Water Management, 179: 55-63. DOI: 10.1016/j.agwat.2016.07.010.

Li Y, Fuchs M, Cohen S, Cohen Y, Wallach R. 2002. Water uptake profile response of corn to soil moisture depletion. Plant Cell and Environment, 25: 491-500. DOI: 10.1046/j.1365-3040.2002.00825.x.

Liu H, Lin H. 2015. Frequency and Control of Subsurface Preferential Flow: From Pedon to Catchment Scales. Soil Science Society of America Journal, 79: 362. DOI: 10.2136/sssaj2014.08.0330.

Liu H, Zhao W, He Z, Liu J. 2015. Soil moisture dynamics across landscape types in an arid inland river basin of Northwest China. Hydrological Processes, 29: 3328-3341. DOI: 10.1002/hyp.10444.

Lv L. 2014. Linking montane soil moisture measurements to evapotranspiration using inverse numerical modeling. In: Dissertations \& Theses Gradworks, Utah State University.

McGowan M, Williams JB. 1980. THE WATER BALANCE OF AN AGRICULTURAL CATCHMENT. I. ESTIMATION OF EVAPORATION FROM SOIL WATER RECORDS. Journal of Soil Science, 31: 217-230. DOI: 10.1111/j.1365-2389.1980.tb02077.x.

Muñoz-Carpena R. 2004. Field Devices For Monitoring Soil Water Content1. EDIS.

N. Mbah C, Nwite J, Njoku C, Ibeh L, S. Igwe T. 2010. Physical Properties of an Ultisol under Plastic Film and No-Mulches and Their Effect on the Yield of Maize. World Journal of Agricultural Sciences, 6(2): 160-165.

Odofin AJ, Egharevba NA, Babakutigi AN, Eze PC. 2012. Drainage beyond maize root zone in an Alfisol subjected to three land management systems at Minna, Nigeria. 216-233. DOI: 10.5897/JSSEM11.143

Ojha R, Corradini C, Morbidelli R, Rao G. 2017. Effective Saturated Hydraulic Conductivity for Representing Field-Scale Infiltration and Surface Soil Moisture in Heterogeneous Unsaturated Soils Subjected to Rainfall Events. Water, 9: 134-151. DOI: 10.3390/w9020134

Qin S, Zhang J, Dai H, Wang D, Li D. 2014. Effect of ridge-furrow and plastic-mulching planting patterns on yield formation and water movement of potato in a semi-arid area. Agricultural Water Management, 131: 87-94. DOI: 10.1016/j.agwat.2013.09.015.

Rahgozar M, Shah N, Ross MA. 2012. Estimation of Evapotranspiration and Water Budget Components Using Concurrent Soil Moisture and Water Table Monitoring. International Scholarly Research Notices, 2012: 1-15. DOI: 10.5402/2012/726806

Read DB, Bengough AG, Gregory PJ, Crawford JW, Robinson D, Scrimgeour CM, Young IM, Zhang K, Zhang X. 2003. Plant roots release phospholipid surfactants that modify the physical and chemical properties of soil. New Phytologist, 157: 315-326. DOI: 10.1046/j.14698137.2003.00665.x.

Rice RC, Bowman RS, Jaynes DB. 1986. Percolation of Water Below an Irrigated Field. Soil Science Society of America Journal, 50: 855-859. DOI: 10.2136/sssaj1986.03615995005000040005x.

Rodriguez-Iturbe I, Porporato A. 2005. Ecohydrology of Water-Controlled Ecosystems. Cambridge University Press, pp: 460.

Rong Y. 2012. Estimation of maize evapotranspiration and yield under different deficit irrigation on a sandy farmland in Northwest China. African Journal of Agricultural Research, 7: 4698-4707. DOI: 10.5897/AJAR11.1213

Séré G, Ouvrard S, Magnenet V, Pey B, Morel JL, Schwartz C. 2012. Predictability of the Evolution of the Soil Structure using Water Flow Modeling for a Constructed Technosol. Vadose Zone J., 11: 59-75. DOI: 10.2136/vzj2011.0069 
Salazar O, Wesström I, Joel A. 2008. Evaluation of DRAINMOD using saturated hydraulic conductivity estimated by a pedotransfer function model. Agricultural Water Management, 95: 1135-1143. DOI: 10.1016/j.agwat.2008.04.011.

Schelde K, Ringgaard R, Herbst M, Thomsen A, Friborg T, Sogaard H. 2011. Comparing Evapotranspiration Rates Estimated from Atmospheric Flux and TDR Soil Moisture Measurements. Vadose Zone J., 10: 78-83. DOI: 10.2136/vzj2010.0060.

Selle B, Minasny B, Bethune M, Thayalakumaran T, Chandra S. 2011. Applicability of Richards' equation models to predict deep percolation under surface irrigation. Geoderma, 160: 569-578. DOI: 10.1016/j.geoderma.2010.11.005.

Shah N, Ross M, Trout K. 2012. Using Soil Moisture Data to Estimate Evapotranspiration and Development of a Physically Based Root Water Uptake Model. InTech.

Slawinski C, Sobczuk H, Stoffregen H, Walczak RT, Wessolek G. 2002. Effect of data resolution on soil hydraulic conductivity prediction. Journal of Plant Nutrition and Soil Science, 165: 45-49. DOI: 10.1002/1522-2624(200202)165:13.0.CO;2-I

Srivastava RK, Panda RK, Halder D. 2017. Effective crop evapotranspiration measurement using time-domain reflectometry technique in a subhumid region. Theoretical and Applied Climatology, 129: 1211-1225. DOI: 10.1007/s00704-016-1841-7.

Su P, Du M, Zhao A, Zhang X. 2002. Study on water requirement law of some crops and different planting mode in oasis. Agricultural Research in the Arid Areas, 20: 79-85. DOI: 10.3321/j.issn:1000-7601.2002.02.019.

Su P, Xie TT, Ding SS. 2010. Water requirement regularity in Linze jujube (Ziziphus jujuba Mill. var. inermis Rehd. cv. Linze jujube) and jujube/crop complex systems in Linze oasis. Chinese Journal of Eco-Agriculture, 18: 334-341. DOI: 10.3724/SP.J.1011.2010.00334.

Su Y, Yang X, Yang R. 2014. Effect of Soil Texture in Unsaturated Zone on Soil Nitrate Accumulation and Groundwater Nitrate Contamination in a Marginal Oasis in the Middle of Heihe River Basin. Environmental Science, 35: 3683-3691. DOI: 10.13227/j.hjkx.2014.10.007.

Suleiman AA, Hoogenboom G. 2007. Comparison of Priestley-Taylor and FAO-56 Penman-Monteith for daily reference evapotranspiration estimation in Georgia. Journal of Irrigation and Drainage Engineering, 133: 175-182. DOI: 10.1061/(asce)0733-9437(2007)133:2(175).

Sun H, Wu R, Li P Shao S, Qi L, Han J. 2008. Rooting Depth of Alfalfa. Acta Agrestia Sinica, 16: 307-312. DOI: 10.11733/j.issn.10070435.2008.03.019.

Wang K, Dickinson RE. 2012. A review of global terrestrial evapotranspiration: Observation, modeling, climatology, and climatic variability. Reviews of Geophysics, 50.2. DOI: 10.1029/2011RG000373.

Wang P, Yu J, Pozdniakov SP, Grinevsky SO, Liu C. 2014. Shallow groundwater dynamics and its driving forces in extremely arid areas: a case study of the lower Heihe River in northwestern China. Hydrological Processes, 28: 1539-1553. DOI: 10.1002/hyp.9682.

Wright JL. 1971. Way Sought to Measure Irrigation Water Needs. Crops \& Soils Magazine, 23.9: 20-211.

Wu X, Zhou J, Wang H, Li Y, Zhong B. 2015. Evaluation of irrigation water use efficiency using remote sensing in the middle reach of the Heihe river, in the semi-arid Northwestern China. Hydrological Processes, 29: 2243-2257. DOI: 10.1002/hyp.10365.

Yang B, Wen X, Sun X. 2015. Irrigation depth far exceeds water uptake depth in an oasis cropland in the middle reaches of Heihe River Basin. Scientific Reports, 5. DOI: 10.1038/srep15206.

Yang J, Mao X, Wang K, Yang W. 2018. The coupled impact of plastic film mulching and deficit irrigation on soil water/heat transfer and water use efficiency of spring wheat in Northwest China. Agricultural Water Management, 201: 232-245. DOI: 10.1016/j.agwat.2017.12.030.

Yong H, Hou L, Hong W, Hu K, Mcconkey B. 2014. A modelling approach to evaluate the long-term effect of soil texture on spring wheat productivity under a rain-fed condition. Scientific Reports, 4. DOI: 10.1038/srep05736.

You DB, Wang JL, Ming-Qiang L, Hua QI, University SA, University QA. 2015. Evapotranspiration of Maize Field in Irrigation Area in Heihe Middle Reaches Using the Penman-Monteith Method. Acta Agriculturae Boreali-Sinica: 139-145. DOI: 10.7668/hbnxb.2015.S1.025.

Zhang Y-L, Wang F-X, Shock CC, Yang K-J, Kang S-Z, Qin J-T, Li S-E. 2017. Influence of different plastic film mulches and wetted soil percentages on potato grown under drip irrigation. Agricultural Water Management, 180: 160-171. DOI: 10.1016/j.agwat.2016.11.018.

Zhao L, Ji X. 2010. Quantification of Transpiration and Evaporation over Agricultural Field Using the FAO-56 Dual Crop Coefficient Approach---A Case Study of the Maize Field in an Oasis in the Middlestream of the Heihe River Basin in Northwest China. Scientia Agricultura Sinica, 43: 4016-4026. DOI: 10.3864/j.issn.0578-1752.2010.19.014.

Zhao L, Zhao W. 2014. Water balance and migration for maize in an oasis farmland of northwest China. Chinese Science Bulletin, 59: 4829-4837. DOI: $10.1007 / \mathrm{s} 11434-014-0482-4$

Zhao L, Zhao W, Ji X. 2015. Division between transpiration and evaporation, and crop water consumption over farmland within oases of the middlestream of Heihe River basin, Northwestern China. Acta Ecologica Sinica, 35: 1114-1123. DOI: 10.5846/stxb201304220778.

Zhao W, Chang X. 2014. The effect of hydrologic process changes on NDVI in the desert-oasis ecotone of the Hexi Corridor. Science China-Earth 
Hydrol. Earth Syst. Sci. Discuss., https://doi.org/10.5194/hess-2018-518

Manuscript under review for journal Hydrol. Earth Syst. Sci.

Discussion started: 15 October 2018

(c) Author(s) 2018. CC BY 4.0 License.

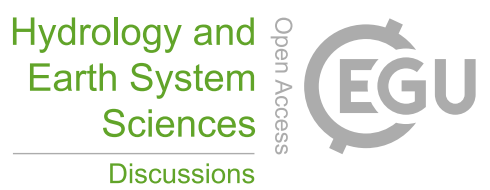

(c) (1)

612 Sciences, 57: 3107-3117. DOI: 10.1007/s11430-014-4927-z.

613 Zhao W, Liu B, Zhang Z. 2010. Water requirements of maize in the middle Heihe River basin, China. Agricultural Water Management, 97: 215-

614 223. DOI: 10.1016/j.agwat.2009.09.011.

615 Zhou H, Zhao W, Zhang G. 2017. Varying water utilization of Haloxylon ammodendron plantations in a desert-oasis ecotone. Hydrological $616 \quad$ Processes, 31: 825-835. DOI: 10.1002/hyp.11060.

617 Zotarelli L, Dukes MD, Morgan, T. K. 2016. Interpretation of Soil Moisture Content to Determine Soil Field Capacity and Avoid Over-Irrigating 618 Sandy Soils Using Soil Moisture Sensors. Agricultural \& Biological Engineering.

619 Zuo, Qiang, Zhang, Renduo. 2002. ESTIMATING ROOT-WATER-UPTAKE USING AN INVERSE METHOD. Soil Science, 167: 561-571. DOI:

620

10.1097/00010694-200209000-00001

621

622 